\title{
Using Google Sites to Communicate with Parents: A Case Study
}

\author{
YEU-HAN (HENRY) LIOU \\ Darunsikkhalai School of Innovative Learning, Thailand
}

\section{Bio Data:}

Yeu-Han (Henry) Liou is currently pursuing his Master's degree in education with State University of New York at Buffalo (USA) and has been a secondary school mathematics teacher at Darunsikkhalai School of Innovative Learning (DSIL) in Thailand for the past four years.

\begin{abstract}
The paper summarizes a case study that took place in a Thai private alternative school - the Darunsikkhalai School for Innovative Learning (DSIL). More specifically, this paper focuses on the usefulness of a class website created by Google Sites in one of the mathematics classes in the school. Questionnaires are distributed to students, parents, and teachers in DSIL to discuss their attitudes, opinions, and experiences towards using class web pages as a medium of communication.
\end{abstract}

\section{Introduction}

Research indicates that there is a direct connection between parent involvement and student success. Harold Hester (as cited in Freedman \& Montgomery, 1994) pointed out it is beneficial to students when parents participate actively in the process of learning. Improved on student behaviors and attitudes, and increased student motivations are all examples of the benefits for students from parent involvement. There are several definitions for parent involvement; the general definition of parent involvement is the interaction that takes place between parents and the school. This could involve parent/teacher communication, parent involvement in school activities, and active parent participation in the student's studying. For the 
purpose of this study, the definition of parent involvement is the communication that occurs between parents and classes. Specifically, this study examines the usefulness of a class website created by Google Sites as a medium to communicate with parents. This case study also focuses on the attitudes, opinions, and experiences of the users of the class web pages.

\section{Description of School}

This study was carried out in a secondary mathematics class of a private Thai school in Bangkok. In order to better understand the setting of the study, a description of the school is provided in this section, and a description of the math class is provided in the following section. The Ministry of Education (MOE) in Thailand recently opened a new track to the educational system the alternative track. Schools on this track "have the freedom to creatively organize the instructional contents" (Choeybal, 2008) to cover the national curriculum designed by the Thai MOE. This case study was carried out in one of the schools in this alternative track - the Darunsikkhalai School for Innovative Learning (DSIL). The school is ten years old, and has almost one hundred students and about forty teachers. Being an alternative school, one of the end goals of DSIL is helping create students who are life-long learners with the expertise in self-learning. In order to achieve this goal, some classes in the school allow students to pace their own learning. In addition, students in these classes are encouraged to self-learn the contents of the classes. Teachers only step in when students encounter questions or difficulties. It is crucial for the teachers in these classes to be aware of each student's progress. 
In a learning style like this, students are held highly accountable for their own learning in these classes.

\section{Description of DSIL Secondary Mathematics Classes}

Class structure and format. There are two secondary mathematics classes in DSIL. Both of them follow the style of student self-learning. One of the classes has a higher level than the other. Students need to complete the contents in the lower level class before they could join the higher level class. This study focused on the higher level class, composed of twelve students, from thirteen to seventeen years old, and one teacher. Students in this mathematics class have the freedom to decide how fast or how slow they wish to cover the contents in the textbook. The students also have the freedom to choose which questions to practice on. As stated earlier, the teacher needs to know the progress of all the students. A typical class would be students selfstudying the mathematics textbook; and if they have any questions, they ask for help from the teacher. At the end of the class, students update the teacher on the contents that they covered in class, and the questions that they practiced on. As a result, every student in the mathematics class has different progress, and the questions that they practiced on vary as well. After receiving the students' updates, the teacher then put them onto the class website, which is created by Google Sites.

Class website created by Google Sites. The class website has been in place for one and half years. The teacher is the only moderator of the website. Students and parents can view and leave comments. The class website 
basically serves as a bulletin board to the students and their parents. Apart from the students' in-class progress updates, information such as class textbooks, class policy, syllabus, students' homework, test dates, test results, messages from teacher to students, and special announcements could also be found on the website posted by the moderator. As requested by the teacher, students were to inform their parents about the class website. All information on the website is open to everyone, including test scores and personal comments from teacher to students. The Google Sites class website only provides updates on the twelve students in the higher level class. Nevertheless, anyone with the URL of the website could see the contents on it.

\section{Research Methodology}

In order to obtain data for the study, different questionnaires were given to three groups of people, students, parents, and teachers. A total of four questionnaires, all in English, were used for this study. The questions consist of both open-ended questions and multiple choice questions. One questionnaire is for the twelve students in the high level mathematics class, out of which eleven of them completed the questionnaire. As for parents, there are two versions of the questionnaire. One version is for the parents of the twelve kids who should have seen the class webpage. Four of these parents answered the questionnaire. The purpose of this questionnaire and the student questionnaire is to find out their perspectives and attitudes on the class website. Another version of the parent questionnaire is for the parents of the students in the lower level mathematics class who have not seen the class 
webpage. Only one parent completed the questionnaire. A link to the class webpage was also provided in the questionnaire for the parents to access. The response of this questionnaire is used to compare with the response obtained from the other version of parent questionnaire. The last questionnaire was sent to ten English teachers in DSIL, out of which seven of them responded. All seven of them created their own English class website with Google Sites. The purpose of this survey is to learn about the teachers' attitudes and concerns towards having a class website, and their experiences on using Google Sites.

\section{Findings and Discussions}

\section{Student Questionnaires}

Students' attitudes towards the class website. All students have internet access at home; some could even go online with their mobile phones. Therefore, accessing the class website is not a problem to this group of students. The overall response of the students to the mathematics class website is positive. A student stated, "I enjoy the website, and it is very environmental friendly! We don't waste papers." It is very interesting that the young generation is having a sense of saving energy and the environment. If class websites could be utilized in all DSIL classes, the school could save a lot of budget on resources, at the same time, saving the environment (Gregory 2006). Anyhow, a few students said that sometimes they could not open the class websites at home; as a result, they did not know what their homework is. This is a problem that needs to have a solution as soon as possible. 
Possible improvements on the mathematics class website. Some interesting suggestions on improving the class website are being brought up by the students. One student suggested putting videos of teacher explaining difficult concepts, so students could use these videos to refresh their memories. Some students also suggested putting interesting mathematics games or quizzes for them to do on the website. All of these are possible on Google Sites because it has a wide range of applications that allow website builders to choose. These applications include pictures, YouTube videos, interactive games, and even online forms which could be customized into multiple choice quizzes. By incorporating all these applications, the class website changes its informative nature to a more interactive and motivating one. Many of them suggested enabling the commenting function on the class website. This showed that the students were not aware of the fact the class website already allows them to do so.

\section{Parent Questionnaires}

Attitudes toward knowing students' learning. There are a total of five parents, aged between forty to fifty years old, who took the questionnaires. The responses from the two versions of parent questionnaire showed shared perceptions on knowing the student's learning. They all agree that it is important for them to know what students learn at school. A parent commented that by knowing about student's learning, parents could have a better idea of the student's learning progress. This parent added that with this information, parents could also play a role in helping developing the 
students. Interestingly, one parent showed his/her concern towards selflearning in the response. This parent commented that parents knowing what students learn at school could serve as a quality control to self-learning.

Mathematics class website. All of these parents use the internet and their emails regularly. This means accessing to the mathematics class website is not be a problem. However, among the four parents whose kids are in the higher-level class, two of them were not aware of the mathematics class website. This finding shows that in order to make sure parents know about the class website, they need to be formally informed by the teacher. Perhaps email would be a good option.

Other responses also showed that the information available on the mathematics class website meet what they want to know. A parent made a suggestion that teacher's opinion on student's learning should also be found on the class website. Another parent also suggested making the class website more communication-friendly. This parent recommended to allow communication between students, parents, and teacher on the class website itself such as leaving messages.

Another interesting finding was the parents' generosity towards allowing other parents and students to see the performance of their kids. Only one parent requires prior permission. Other parents felt comfortable with showing their kids' performances without requiring any sort of permission from them. One of the reasons for showing everyone's grades is that DSIL focuses on the students' learning process instead of summative grades and 
results. Therefore, if the parents and students understood the concept of the school, they would view the posting of their grades as a tracker of their own learning, instead of a comparison with other students.

\section{Teacher Questionnaires}

Attitudes toward parents knowing students' learning. All seven responses agreed that it is very important for parents to know what students learn at school. One teacher commented that "parental involvement in their children's education is the number one predictor of student achievement". Many of them mentioned that once parents know about the students' learning, they could reinforce the contents at home. One teacher added knowing student's learning is beneficial to the communication between parents and teachers. With this information, parents could "share their opinions and/or suggestions with the teaching staff."

Attitudes towards the use of a class website. As mentioned earlier, all seven teachers have their own class website. Most teachers update their websites regularly from two to three times per week to every two weeks. However, two teachers brought up an interesting point regarding their motivations of updating the websites. One of them said "[a]t first, (I update mine) weekly. However, having noticed that the parents rarely, if ever, check the website, I used it less." As a result, the frequency of the teachers updating their websites drops when they found out that only a few parents check on the website. Anyhow, all teachers agreed that it is easier and faster to update the websites daily than to write student reports every two weeks. One teacher 
commented that the biggest challenge of the class websites would the "lack (of) visual and nonverbal cues (e.g., tone of voice or body language)." (Bouffard 2008)

Personal experience on Google Sites. All seven teachers built their class websites with Google Sites. Only a few negative points were brought up by these teachers. The long addresses of the websites could be difficult for teachers to give to their students. This problem could be solved by using free online tools that shorten web addresses, such as Google url shortener. A teacher also suggested to link all the class websites to the DSIL school website, which could also resolve this issue.

All seven teachers agreed that it is fairly easy to create a class website with Google Sites. When asked if it is necessary to provide a training session for teachers who are new to Google Sites, five teachers think that a training session would not be necessary. A teacher stated, “It was my first website and the program (Google Sites) was easy to follow. I have encountered a few bugs from time to time, but overall the usability is very good." Simplicity, ease of use, and free of charge are the main reasons why these teachers like Google Sites. One of them even incorporated Google Sites in his personal blog. Overall, these teachers have positive feedbacks on using Google Sites to create class websites.

\section{Conclusion}

As stated in the article of Black and Wiliam (1998), classroom is like a black box to the society these days. To a certain extent, apart from the people who 
are in the black box, the teachers and students, the public does not know exactly what is happening inside. One way to make this black box more transparent is to incorporate parent involvement into the school operation. Communicating with the parents is one example of parent involvement. Society has changed over the years. As people's lifestyle changes, methods of communicating with the parents should evolve too. Teachers should take advantage of modern technologies, such as class websites, to reach out to the parents more efficiently and precisely.

\section{References}

Black, P. \& Wiliam, D. (1998). Inside the black box: Raising standards through classroom assessment. Phi Delta Kappan, 80 (2), 1-20.

Bouffard, S. (2008, July). Tapping into technology: The role of the internet in family-school communication. Family Involvement Research Digest: Harvard Family Research Project. Retrieved from http://www.hfrp.org/publications-resources/browse-ourpublications/tapping-into-technology-the-role-of-the-internet-infamily-school-communication

Choeybal, P. (2008). A proposed management model for an alternative school in Thailand, Educational Journal of Thailand, Vol. 2 (1).

Freedman, E. \& Montgomery, J. F. (1994). Parent education and student achievement. Thrust for Educational Leadership, 24, 40-45. 
Kats, G. (2006, October). Greening America's schools: Costs and benefits.

Retrieved from

http://www.usgbc.org/ShowFile.aspx?DocumentID=2908

\section{Appendix - Questionnaires}

All questionnaires are being distributed through www.SurveyGizmo.com in the following links.

Student questionnaire:

http:/ / edu.surveygizmo.com/s3/498300/Class-Website-Survey-extendedstudent

Parent questionnaire (whose kids are in the higher level class):

http://edu.surveygizmo.com/s3/497727/Class-Website-Survey-ExtendedParents

Parent questionnaire (whose kids are in the lower level class):

http:/ / edu.surveygizmo.com/s3/498296/Class-Website-Survey-core-parents English teacher questionnaire:

http:/ / edu.surveygizmo.com/s3/498304/Class-Website-Survey-teachersENS 